\title{
Research Article: Decision-making pattern of rural women beneficiaries of National Rural Livelihood Mission in Rewa district of M.P.
}

\author{
Aparna Singh, Sanjay Singh, Nirmala Singh and Ajlan Khan
}

Article Chronicle : Received :

23.11.2017;

Revised :

05.01.2018;

Accepted :

21.01.2018

KEY WoRDS :

Decision making

pattern, Rural women,

National rural

livelihood mission
SUMMARY : Involvement of rural women in decision-making process has been of great importance because they perform every household activity and major farm activities with great devotion and excellent capabilities. Keeping this in view, the present study was conducted to know the level of involvement of rural women in the decision-making process in agriculture and allied activities. The present study was conducted in Rewa district of M.P. since the National Rural Livelihood Mission (NRLM) project has been running in the district since 2015 for improving the livelihood and empowerment of women. Hence, the sample of the study was consisted of 120 rural women beneficiaries of National Rural Livelihood Mission. The study revealed that 45.00 per cent of the total respondents exhibited low level of decision making pattern followed by 30.83 per cent had medium and only 24.16 per cent had high decision making ability in farming and allied activities The study suggests that the rural women should be actively involved in awareness and capacity building programmes of rural and agricultural development for enhancing their involvement in decision-making process.

How to cite this article : Singh, Aparna, Singh, Sanjay, Singh, Nirmala and Khan, Ajlan (2018). Decision-making pattern of rural women beneficiaries of National Rural Livelihood Mission in Rewa district of M.P. Agric. Update, 13(1): 88-92; DOI : 10.15740/HAS/AU/13.1/88-92.
Author for correspondence :

Aparna Singh College of Agriculture, Rewa (M.P.) India

See end of the article for authors' affiliations 